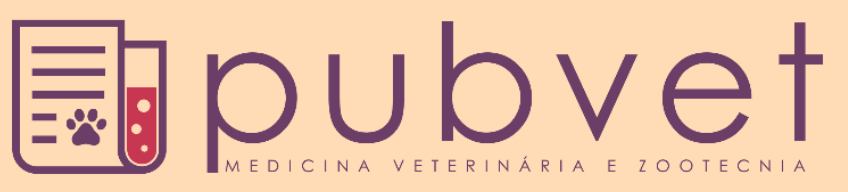

https://doi.org/10.31533/pubvet.v15n09a901.1-10

\title{
Micotoxinas e seu alarmante alcance na bovinocultura: Revisão
}

\author{
Ellen Paola Dallmann ${ }^{1} \bullet$, Júlia Hoffmann Passos ${ }^{1} \bullet$, Lara Sofia Treis ${ }^{1}{ }^{\ominus}$, Maria Clara Reif

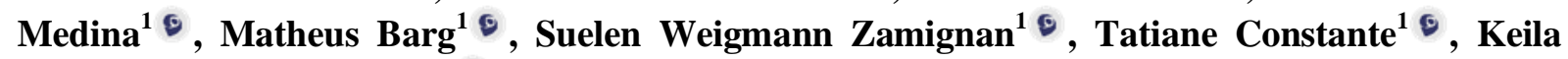 \\ Zaniboni Siqueira Batista ${ }^{2 *} \odot$ (D)
}

${ }^{I}$ Acadêmico, Departamento de Medicina Veterinária, Universidade Regional de Blumenau-FURB, Brasil.

${ }^{2}$ Docente, Departamento de Ciências Naturais, Universidade Regional de Blumenau-FURB, Brasil.

* Autor para correspondência, E-mail: keila_siqueira@furb.br

\begin{abstract}
Resumo. As micotoxinas são metabólitos gerados por fungos filamentosos, encontrados no ambiente e em alimentos, como pastagem e cereais, destinados à alimentação bovina. A contaminação por micotoxinas é uma das grandes preocupações no que concerne aos rebanhos do mundo todo. A problemática se inicia durante a produção e armazenamento incorretos do alimento, quando há condições favoráveis à proliferação dos fungos causadores da contaminação. Essas micotoxicoses podem gerar diversos danos, entre eles, carcinogênicos, neurológicos e hepáticos. O objetivo desta revisão bibliográfica foi discorrer a respeito das principais micotoxinas, os agentes etiológicos que as sintetizam, e as micotoxicoses que acometem os bovinos. Para tanto, foram utilizadas as bases de busca Scielo, Pubmed e Portal Capes, além de sites oficiais, utilizando-se as palavras-chave "micotoxinas", "micotoxicoses" e "intoxicação fúngica", com enfoque em bovinos.
\end{abstract}

Palavras-chave: Bos taurus, fungos filamentosos, intoxicação alimentar fúngica, medicina veterinária

\section{Mycotoxins and their alarming reach to cattle: Review}

Abstract. Mycotoxins are metabolites from filamentous fungi founded in environment and food, as pasture and cereals, intended for cattle feeding. Herd mycotoxin contamination is one of the big preoccupations around the world. The incorrect food production and storage, when conditions favor to proliferation of fungi that cause contamination, is problematic. These mycotoxins can cause carcinogenic, neurological and hepatic damages. The purpose of this literature review was to highlight the main mycotoxins, the etiologic agents, and mycotoxicosis that affect cattle. For this purpose, the Scielo, Pubmed and Portal Capes search bases were used, in addition to official websites, using the keywords "mycotoxins", "mycotoxicosis" and "fungal intoxication", with a focus on cattle.

Keywords: Bos taurus, fungi, mycotoxicosis, veterinary medicine

\section{Introdução}

O termo micotoxina refere-se a diversos metabólitos tóxicos ou secundários que causam alterações patogênicas em humanos e animais. São sintetizados por uma grande variedade de fungos filamentosos em crescimento, os quais realizam reações enzimáticas consecutivas quando há acúmulo de metabólitos primários (Dias, 2018; Serrano-Coll \& Cardona-Castro, 2015).

As toxinas fúngicas de maior importância para a saúde pública e animal, bem como para economia agrícola, são produzidas pelos gêneros Aspergillus, Penicillium, Fusarium, Neotyphodium e Claviceps (Mallmann et al., 2007). Sua síntese pode ocorrer antes e após a colheita, armazenamento, transporte, processamento e alimentação dos animais, dependendo da presença de nutrientes, umidade, calor e $\mathrm{pH}$ (Dias, 2018). 
Quando as micotoxinas são inaladas, ingeridas ou entram em contato direto têm capacidade de gerar intoxicações, conhecidas como micotoxicoses (Serrano-Coll \& Cardona-Castro, 2015). Os efeitos ocasionados variam, podendo surgir quadros de neurotoxicidade, nefrotoxicidade, hepatotoxicidade, toxicidade pulmonar e endócrina, processos cancerígenos, imunossupressão, alterações dérmicas e inibição de absorção de nutrientes a nível gastrointestinal (Serrano-Coll \& Cardona-Castro, 2015).

O presente artigo de revisão objetiva discorrer a respeito das principais micotoxinas e micotoxicoses que afetam bovinos de criação, apresentando os principais fungos que as sintetizam e as medidas preventivas e profiláticas que podem ser adotadas. Trata-se de uma revisão integrativa, utilizando-se os seguintes bancos de dados: SciELO, Pubmed, Portal CAPES, além de sites oficiais do Ministério da Agricultura, Pecuária e Abastecimento (MAPA), Embrapa e da Sociedade Americana de Fitopatologia (The American Phytopathological Society). As palavras-chave utilizadas foram "micotoxinas", "micotoxicoses" e "intoxicação fúngica" associadas à palavra "bovinos", em português, inglês e espanhol, nos últimos 15 anos.

\section{Micotoxinas e micotoxicoses em bovinos}

Dentre os fungos responsáveis por causar micotoxicoses em bovinos, destacam-se os dos gêneros Claviceps spp., Aspergillus spp., Fusarium spp., Penicillium spp., Neotyphodium spp., Acremonium spp., Myrothecium spp., Trichothecium spp. e Pithomyces sp. Estes produzem micotoxinas capazes de gerar ações prejudiciais à espécie, como consta no Quadro 1.

\section{Fungos e suas micotoxinas}

Aspergillus spp.

Os fungos do gênero Aspergillus são saprófitos, aeróbios e de crescimento rápido (Quinn et al., 2018). Podem estar presentes no solo, nos alimentos e na vegetação, além de serem encontrados, secundariamente, no ar e na água. Com certa frequência, estes fungos estão presentes em matéria vegetal fermentada como, por exemplo, feno e silagem. A forma de transmissão deste gênero é, geralmente, pela ingestão ou inalação (Klich \& Pitt, 1988).

Quanto às suas características morfológicas, o Aspergillus possui hifas septadas, estruturas produtoras de esporos assexuadas, que estão presentes nos conidiósporos. Ao final dos conidiósporos, encontra-se uma vesícula, a qual é recoberta por camadas de fiálides em forma de cantil, onde surgem cadeias de conídios pigmentados, responsáveis pela coloração das colônias do fungo (Klich \& Pitt, 1988). Estas colorações no reverso podem ser verde-azulada, preta, marrom ou amarelas, variando de acordo com a espécie e a condição do cultivo (Quinn et al., 2018).

Algumas das micotoxinas produzidas por este gênero são conhecidas como Aflatoxinas, dos tipos B1, G1, B2 e G2, as quais são pouco degradadas no rúmen. Todavia, caso a Aflatoxina B1 seja degradada, produz o aflatoxicol, altamente tóxico para a microbiota ruminal, afetando seu crescimento e atividade metabólica (Vedovatto et al., 2020).

Estas micotoxinas são metabolizadas no fígado, e possuem propriedades carcinogênicas, imunossupressoras e também mutagênicas. Uma intoxicação crônica por Aflatoxinas pode ocasionar danos ao fígado e redução do consumo da matéria seca, além de dores abdominais, cólica e diarreia. Bovinos leiteiros têm sua produção diminuída e bovinos em fase de crescimento apresentam baixo ganho de peso. Caso ocorra uma intoxicação aguda, apesar de ser rara, os animais acometidos podem apresentar edema submandibular, fotodermatite, algumas alterações nervosas e diarreia (Pierezan et al., 2010; Vedovatto et al., 2020).

As micotoxinas isoladas do A. clavatus são a triptoquivalona, nortriptoquivalona, triptoquivalina e outros compostos como citocalasina $\mathrm{E}$ e K e patulina; no entanto, não foram realizados testes isolados com essas substâncias, em ruminantes, para verificar sua atuação em intoxicações pelo fungo. Ademais, é importante ressaltar o fato de que a patulina pode ser encontrada em outros fungos como Penicillium, Gymnoascus e Paecilomyces. Há hipóteses de que a patogênese dessa intoxicação se dá por meio da ação conjunta de diversas micotoxinas (Morais, 2018). 
Quadro 1. Principais fungos e micotoxinas que afetam bovinos.

\begin{tabular}{|c|c|c|c|}
\hline Fungos & Plantas/Alimentos & Micotoxinas & Ações \\
\hline Aspergillus clavatus & Cereais e outros alimentos & $\begin{array}{l}\text { Triptoquivalona, nortriptoquivalona, } \\
\text { triptoquivalina, citocalasina E e } \\
\mathrm{K} \text {, e patulina }\end{array}$ & Neurotóxicas \\
\hline $\begin{array}{l}\text { Aspergillus flavus, } A . \\
\text { parasiticus, A. nomius }\end{array}$ & $\begin{array}{l}\text { Grãos de cereais, } \\
\text { amendoins, caroço de } \\
\text { algodão, soja, milho, entre } \\
\text { outros }\end{array}$ & $\begin{array}{l}\text { Aflatoxinas tipos: B1, B2, G1 e } \\
\text { G2 }\end{array}$ & $\begin{array}{l}\text { Genotóxicas, Teratogênicas, } \\
\text { Hepatotóxicas, } \\
\text { Carcinogênicas, Mutagênicas, } \\
\text { Imunossupressoras }\end{array}$ \\
\hline Claviceps paspali & Gramíneas Paspalum spp. & $\begin{array}{l}\text { Paspalitrem } \quad \text { A, } \quad \text { B, } \quad \text { C } \\
\text { paspalinina (Indol diterpenos) }\end{array}$ & Neurotóxicas \\
\hline Claviceps purpurea & $\begin{array}{l}\text { Sementes de gramíneas e } \\
\text { outros cereais }\end{array}$ & $\begin{array}{l}\text { Ergotamina, ácido lisérgico e } \\
\text { ergonovina }\end{array}$ & Neurotóxicas \\
\hline $\begin{array}{l}\text { Fusarium graminearum, } \\
\text { F. culmorum }\end{array}$ & $\begin{array}{l}\text { Zea mays, Triticum aestivum, } \\
\text { Sorghum bicolor, Hordeum } \\
\text { vulgare, Secale cereale }\end{array}$ & Zearalenona & $\begin{array}{l}\text { Problemas reprodutivos; } \\
\text { Aborto; Efeito estrogênico }\end{array}$ \\
\hline $\begin{array}{l}\text { Fusarium sporotrichioides, } \\
\text { F. graminearum, F. poae, e } \\
\text { F. culmorum, Myrothecium } \\
\text { spp. e Trichothecium } \text { spp. }\end{array}$ & $\begin{array}{l}\text { Grãos de cereais, palhas, } \\
\text { feno e silagem }\end{array}$ & $\begin{array}{l}\text { Tricotecenos tipos: A (toxina T-2, } \\
\text { seus metabólitos desacetilados) e } \\
\text { B (deoxinivalenol e seus derivados } \\
\text { acetilados - nivalenol, etc) }\end{array}$ & $\begin{array}{l}\text { Problemas gastrointestinais } \\
\text { (afeta o rúmen em doses } \\
\text { altas), hemorragias, vômitos } \\
\text { e dermatites }\end{array}$ \\
\hline $\begin{array}{l}\text { Fusarium proliferatum e } \\
\text { F. verticillioides }\end{array}$ & $\begin{array}{l}\text { Grãos de cereais, } \\
\text { principalmente milho }\end{array}$ & $\begin{array}{l}\text { Fumonisina tipos: B1 (maior } \\
\text { importância zootécnica) e B2 }\end{array}$ & $\begin{array}{l}\text { Problemas gastrointestinais } \\
\text { (afeta o rúmen em doses } \\
\text { altas) }\end{array}$ \\
\hline $\begin{array}{l}\text { Neotyphodium lolii } \\
\text { Acremonium lolii }\end{array}$ & Lolium perenne & $\begin{array}{l}\text { Paxilina, lolitremo } \\
\text { ergovalina, peramina }\end{array}$ & Neurotóxicas, Mitotóxicas \\
\hline $\begin{array}{l}\text { Neotyphodium } \\
\text { coenophialum }\end{array}$ & $\begin{array}{l}\text { Holcus lanatus, Poa } \\
\text { pratensis L., multiflorum } \\
\text { L., Festuca arundinacea }\end{array}$ & Ergot alcaloides & $\begin{array}{l}\text { Neurotóxicas e alterações da } \\
\text { circulação sanguínea }\end{array}$ \\
\hline Penicillium spp. & $\begin{array}{l}\text { Grãos, cereais, frutas, } \\
\text { legumes e silagem }\end{array}$ & Ocratoxina, patulina e citrinina & $\begin{array}{l}\text { Problemas gastrointestinais } \\
\text { e pulmonares }\end{array}$ \\
\hline Pithomyces sp. & Lolium perenne & Esporidesmina & $\begin{array}{l}\text { Toxicidade biliar e hepática, } \\
\text { Nefrotoxicidade }\end{array}$ \\
\hline
\end{tabular}

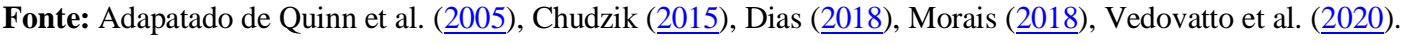

\section{Fusarium spp.}

Fungos do gênero Fusarium são saprófitas, habitando o solo, a água e plantas (Tibola et al., 2015), no solo podem persistir na forma de clamidósporos e também micélios (Delavenne et al., 2011). Microscopicamente, o fungo possui hifas hialinas septadas e irregulares; enquanto na macroscopia, apresenta aspecto filamentoso e textura algodonosa, e possui uma coloração branca, que com o passar do tempo pode tornar-se rósea, cinza e até violeta, e seu reverso apresentando coloração variável, mais clara que o verso (Tibola et al., 2015).

A zearalenona, uma micotoxina liberada pelo fungo do gênero Fusarium spp., induz hiperestrogenismo em fêmeas bovinas. Tal intoxicação pode provocar aumento uterino, inchaço da vulva, glândulas mamárias e mamilos, prolapso da vagina ou reto, prolongamento ou interrupção do cio e pseudociese (Santos et al., 2010). Outra micotoxina descrita é a fumonisina, tóxica para o metabolismo ruminal, quando ingerida em doses altas (Vedovatto et al., 2020).

Os tricotecenos podem ser classificados como toxinas gastrintestinais, dermatotoxinas, imunotoxinas, hematotoxinas e genetoxinas. Entre eles, destaca-se o desoxinivalenol (DON) ou vomitoxina, que possui efeitos tóxicos como decréscimo ou rejeição de alimentação, vômitos e 
distúrbios digestivos com consequente perda de peso (Santos et al., 2010). Pode causar, também, hemorragias e dermatites, além de ser hepatotóxico, nefrotóxico e carcinogênico (Mezzari \& Manole., 2012). A toxina T2, outra representante dos tricotecenos, tem como sinais a irritação, hemorragias e necrose no trato digestivo, depressão no processo regenerativo realizado pela medula óssea e baço, alteração da função dos sistemas imunológico e reprodutor (Iamanaka et al., 2013).

\section{Penicillium spp.}

Os fungos desse gênero se adaptam a vários tipos de ambientes, podendo crescer inclusive em temperaturas de refrigeração. Constituído, na maioria, por saprófitas oportunistas, não exigem muitos nutrientes para sua sobrevivência e toleram variadas condições ambientais. É um gênero bastante abrangente, atualmente com 354 espécies aceitas (Visagie et al., 2014). Podem ser encontrados no solo, ar, vegetação, nos alimentos e em locais internos. Na morfologia microscópica observam-se conídios, os quais são produzidos em cadeia a partir das fiálides, formando assim, uma estrutura denominada penicillus (do latim, pequeno pincel), com hifas hialinas e septadas; e na macroscópica possui uma coloração azul-esverdeada e aspecto algodonoso (Garvil et al., 2015).

As espécies frequentemente encontradas em milhos e derivados são $P$. funiculosum, $P$. citrinum e $P$. oxalicum, e estão associadas a liberação de ocratoxinas e citrinina (Prado, 2014). Dependendo das condições do ambiente e da espécie acometida, a elevada população desse gênero pode gerar uma maior produção das micotoxinas, que pode afetar tanto a saúde animal quanto a humana. $\mathrm{O}$ fungo Penicillium spp. é cosmopolita, está diretamente envolvido na decomposição de matéria orgânica no solo e é antagonista de espécies de fitopatógenos (Garvil et al., 2015; Visagie et al., 2014).

A ocratoxina é uma das micotoxinas produzidas pelo fungo Penicillium, degradada no rúmen por protozoários, o que ocasiona uma diminuição na toxicidade. Quanto mais alimento concentrado o animal receber, maior será a degradação desta micotoxina; porém, se a quantidade presente na dieta não for muito alta, a ruminação os protegerá dos efeitos tóxicos. Caso a toxina não seja degradada, ela é então absorvida no intestino delgado e se liga à albumina, sendo levada para vários tecidos, principalmente rins. A toxina possui um efeito inibidor da síntese proteica, interferindo na transcrição de várias proteínas. Sua oxidação gera a ocratoxina A-quinona, que se liga no DNA, gerando mutações e tumores. Entre os efeitos observados em bovinos, os neurotóxicos, carcinogênicos e hepatotóxicos estão entre os principais. Outra micotoxina formada por esse fungo, é a patulina, esta é responsável por uma grande ação antimicrobiana no rúmen, que acaba afetando negativamente a fermentação ruminal. Alguns dos sinais de intoxicação animal são agitação, convulsões e hemorragia na forma aguda; enquanto na crônica, os efeitos são neurotóxicos, cancerígenos e imunotóxicos. Todavia, por ser altamente degradada no rúmen, os riscos são menores (Vedovatto et al., 2020).

\section{Myrothecium spp.}

Myrothecium roridum e $M$. verrucaria são fungos saprófitas, de solo e tecidos vegetais, tanto vivos quanto em decomposição (Duval et al., 2010). Em segundo plano, podem estar presentes na água, ar e em cereais, palhas, feno e silagem, predispondo à infecção fúngica, uma vez que os ruminantes se contaminam ao ingerir os materiais fermentados (Vedovatto et al., 2020). Ainda há possibilidade de contaminação por via aérea, levando em consideração a capacidade de disseminação do fungo juntamente com as estruturas reprodutivas e/ou sementes de plantas contaminadas permitindo sua inalação (Duval et al., 2010).

Além disso, os bovinos podem apresentar morte súbita devido às altas doses de roridinas, micotoxinas presentes em fungos desse gênero. São capazes de contaminar os ruminantes na ingestão do azevém e trevo branco de forragens armazenadas, sendo que, desta forma, esses alimentos fermentados ficam suscetíveis à contaminação pelo fungo e suas micotoxinas. Quando expostos a quantidades menores de roridina, porém por um longo período, os animais podem manifestar perda de peso e, por isso, um retardo no crescimento, podendo evoluir para a morte (Quinn et al., 2005). 


\section{Trichothecium spp.}

Segundo informações do Sistema de Atenção Primária à Saúde o Trichothecium é um fungo mitospórico filamentoso que afeta principalmente a vegetação em decomposição e o solo. Assim como o Myrothecium spp., pode afetar plantas vivas e causar distúrbios gastrointestinais em animais que as ingerirem em grande quantidade (Duval et al., 2010).

O Manual de Análise Sanitária de Sementes (Brasil, 2009) mostrou que sementes infectadas por esse fungo geram colônias com intensa produção de esporos, formando uma massa densa. Os conidióforos são hialinos, retos e separados, produzindo conídios no ápice, os quais permanecem em grupos ou cadeias, geralmente ligados lado a lado. É possível observar os conídios bicelulares, ovoides ou

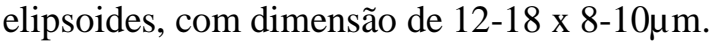

As micotoxinas sintetizadas por esse gênero são denominadas de tricotecenos, principalmente os não-macrocíclicos dos tipos $\mathrm{A}$ e $\mathrm{B}$, destacando-se a toxina $\mathrm{T} 2$ e o desoxinivalenol (DON) e suas variações, respectivamente. No geral, a toxicidade dos tricotecenos está associada à inibição da síntese proteica de eucariotos, mediante a ligação na subunidade $60 \mathrm{~S}$ do ribossomo e a inibição da transferase peptídica (Freire et al., 2007; Furlong, 1992; Marochi et al., 1996). Por consequência do seu mecanismo, células em divisão do trato gastrointestinal, da pele, de tecidos eritroides e linfoides são afetadas. Logo, os animais podem manifestar sinais clínicos como perda ou baixo ganho de peso, necrose dérmica, diarreia sanguinolenta, lesões herniantes e diminuição na produção de leite, ovos, entre outros (Furlong, 1992).

Especificamente, a toxina T2 é considerada um metabólito de alta toxicidade, que implica em hematotoxicidade e imunotoxicidade. Por outro lado, o DON é identificado com maior frequência e é capaz de desencadear alterações dose-dependente, ou seja, em doses maiores causa vômitos, náuseas e diarreia; enquanto em doses menores provoca redução alimentar e, assim, perda de peso (Freire et al., 2007; Furlong, 1992; Marochi et al., 1996).

\section{Pithomyces sp.}

Fungos do gênero Pithomyces são caracterizados como ascomicetos pertencentes a Família Pleosporaceae. Morfologicamente, vão de subesféricos a uma forma de clava, de coloração marrom e com conídios variavelmente septados, carregados no ápice de conidiósporos que surgem das laterais de hifas (Cunha et al., 2014; Dias, 2018).

O espécime $P$. chartarum, fungo cosmopolita, mistospórico e saprófita das plantas, é a única associada a um estágio sexual (Cunha et al., 2014; Dias, 2018). Seus esporos são responsáveis por liberar uma micotoxina denominada esporidesmina, que acarreta a pitomicotoxicose, uma patologia marcada por quadros de eczema facial, toxicidade hepática e biliar, podendo evoluir para a fotossensibilização, uma dermatite decorrente da sensibilidade à radiação ultravioleta (UV), quando há um agente fotodinâmico na circulação periférica (Dias et al., 2018; Moreira et al., 2018).

Algumas condições são necessárias para o desenvolvimento desse fungo, incluindo temperaturas adequadas (temperatura ótima de $24^{\circ} \mathrm{C}$ ), umidade e substratos, dentre os quais se destacam a matéria vegetal morta de folhas e caules de leguminosas e de gramíneas. Ainda, o P. chartarum é encontrado em pastagens cultivadas ou nativas que, quando alcançam níveis tóxicos, conforme o número de esporos presentes, e são consumidas, causam disfunções hepáticas e impedem a excreção da filoeritrina (pigmento transformado no rúmen a partir da clorofila) pelo ducto biliar, logo, permanecendo na corrente sanguínea do animal e gerando a fotossensibilização (Moreira et al., 2018; Motta et al., 2000; Rodríguez et al., 2010).

A síntese da esporidesmina pelo fungo varia de região para região. Essa micotoxina pertence à classe das epipolitiodioxopiperazina (ETP) e é produzida no micélio, concentrando-se nos esporos durante a esporulação, a qual é intensificada na presença de radiação UV. O mecanismo de toxicidade da esporidesmina varia conforme a espécie; os esporos são absorvidos no trato gastrointestinal e o epitélio dos ductos biliares representa o principal sítio de ação da micotoxina (Dias, 2018). A esporidesmina também pode afetar os rins, todavia, em menor grau que o fígado. Neste, o metabólito participa de um ciclo de oxidação-redução, o qual libera radicais livres de oxigênio que danificam o epitélio, levando a necrose, inflamação, espessamento da parede e bloqueio do fluxo biliar (Dias, 2018). Em bovinos, as 
manifestações incluem irritação, edema de zonas pigmentadas da pele, formação de crostas, corrimento ocular seromucoso a mucopurulento, inflamação das pálpebras, sialorreia, inquietude, busca por locais sombreados, constipação, urina frequente e prolongada, sendo que nem todos podem evidenciar a fotossensibilidade (Moreira et al., 2018; Motta et al., 2000; Rodríguez et al., 2010).

\section{Neotyphodium spp.}

Os fungos do gênero Neotyphodium, comumente encontrado em plantas de Festuca sp., são caracterizados como deuteromicetos, os quais possuem ausência ou baixa ocorrência de reprodução sexual. Além disso, são endófitos, pois possuem associação simbiótica com as plantas (Nunes \& Mittelman, 2016). O mesmo autor apresenta que a intoxicação por esse fungo pode ocorrer em bovinos, ovinos e equinos. Nesse estudo, foi demonstrado que o endófito observado nas sementes de azevém anual é pouco ramificado e com largura de 1-2 $\mu \mathrm{m}$. O fungo $N$. coenophialum possui características usadas para sua identificação, como aspecto típico mais enrolado, em forma de espiral e altamente septado.

A intoxicação por estes fungos apresenta sintomas oscilantes, que vão desde a elevação da temperatura corporal, perda de brilho da pelagem, inapetência, abortos, gangrenas em extremidades como orelhas e diminuição do ganho médio de peso em cerca de $50 \%$, o que relaciona à baixa fertilidade na criação de proles. Sua manifestação ocorre principalmente em gados bovinos, ovinos e equinos, gerando problemas na economia dos pecuaristas, a partir da toxicose causada pelo consumo de pastos com Festuca arundinaciea e Lolium perene infectados por $N$. coenophialu e $N$. lolii (Nunes \& Mittelman, 2016).

Uma das micotoxinas do fungo abordado, a paxilina, pode causar uma doença chamada de cambaleio pelo penitrema, nome dado pelo fato de ser provocada principalmente pelas penitremas verruculogeno. Essa patologia foi descrita na Nova Zelândia, Austrália, EUA e África do Sul e seus sinais clínicos são semelhantes àqueles do cambaleio pelo azevém, típicos das intoxicações tremorgênicas (Quinn et al., 2005). Nesse sentido, observam-se tremores musculares, ataxia, hipermetria, aumento da base de sustentação, desequilíbrio, estado de alerta e, raramente, morte (Pessoa et al., 2010). Este gênero de fungo produz alcaloides do tipo Ergot, os quais não são inativados pelos microrganismos ruminais. Além disso, podem causar alterações no metabolismo e na população ruminal, em especial para bactérias fibrolíticas, responsáveis pela digestão das fibras. Estes compostos agem em vias regulatórias, alterandoas, como por exemplo a função endócrina, motilidade do trato gastrointestinal, regulação da temperatura corporal, entre outros, com sinais clínicos da intoxicação sendo os resultados observados nestas alterações (Vedovatto et al., 2020).

Intoxicações por estes alcaloides em bovinos podem gerar dois distúrbios metabólicos: Summer Slump ("Queda de Verão") e Fescue foot ("Pé de Festuca"). O Summer Slump ocasiona, entre outros, baixas taxas de crescimento, elevação da temperatura corporal, aumento da frequência respiratória e salivação, os quais podem ser agravados, caso a temperatura ambiental esteja elevada. Isto pode ocasionar alterações comportamentais e redução do consumo de alimentos pelo animal afetado. O Fescue foot é menos significativo e pode ocasionar problemas no inverno, como inchaço e claudicação, principalmente nos membros pélvicos, além de ocorrer gangrena e necrose nas extremidades (Vedovatto et al., 2020).

\section{Acremonium spp.}

Os fungos do gênero Acremonium spp. são cosmopolitas, ocorrendo em ambientes temperados e tropicais (Mussi-Dias et al., 2012), saprófitos, endofíticos e capazes de produzir compostos orgânicos voláteis que possuem atividade antimicrobiana em plantações, por isso são amplamente utilizados para esta finalidade (Santos, 2014). No entanto, podem ocasionar doenças em animais pelo fato de serem agentes de micoses oportunistas e subcutâneas (Braz et al., 2009). Também são encontrados em esgotos e plantas aquáticas, ocasionando lesões cutâneas e até infecções disseminadas nos animais e humanos. Microscopicamente, o Acremonium spp. apresenta hifas septadas de parede fina, e macroscopicamente possuem um aspecto filamentoso, podendo ter as cores creme, marrom, cinza e também rosa (Schmidt \& Osborn, 1993). Ao crescerem em culturas, estes fungos são parecidos com o Fusarium spp. nos estágios iniciais, pois sobre as delgadas fiálides produzem pequenos conídios (Mezzari \& Manole., 2012). 
No que concerne às doenças causadas pelas micotoxinas desse fungo, o cambaleio pelo azevém é uma das micotoxemias mais comuns em bovinos e é provocado, principalmente, pelas lolitremas. Essa enfermidade, como citado anteriormente, é muito semelhante ao cambaleio pelo penitrema, já que possui os mesmos sinais clínicos, se diferenciando apenas pelo fato de possuir um quadro neurológico mais grave. Quanto às outras toxinas fúngicas produzidas pelo $A$. lolii, a patogenia se manifesta da mesma maneira que a do Neotyphodium spp. (Quinn et al., 2005).

\section{Claviceps spp.}

A espécie Claviceps paspali é um fungo ascomiceto que pertence à família Clavicipitaceae, especializado na infecção de ovários de inflorescências de gramíneas em desenvolvimento (fase assexuada), como por exemplo as do gênero Paspalum spp. Para que ocorra a micotoxicose, o animal precisa ingerir as gramíneas contaminadas com os escleródios do C. paspali, os quais abrangem o Paspalitrem A, B, C e Paspalinina. Seu mecanismo de ação ainda não foi elucidado, mas há indícios de que possivelmente essas micotoxinas inibam a função do receptor GABA ao se ligar nele, mais especificamente no local de influxo ou perto deste (Morais et al., 2019).

Outra espécie dessa família é a Claviceps purpurea, caracterizada como um fungo ascomiceto, capaz de infectar sementes de gramíneas, centeio e outros cereais, como trigo, cevada e arroz. Após a infecção da semente ou da pastagem, o fungo forma uma massa micelial branca, e posteriormente é formado um escleródio de coloração marrom-escuro (Morais et al., 2019). A ingestão de sementes ou cereais contaminados gera o ergotismo, condição que é capaz de gerar formas clínicas distintas, como a distérmica, gangrenosa, reprodutiva e nervosa. Sendo esta última, menos frequente na espécie bovina (Hemckmeier et al., 2018).

\section{Prevenção e tratamento}

Como métodos de prevenção das micotoxicoses que afetam os bovinos, é essencial utilizar-se da detoxificação de alimentos e rações contaminados com micotoxinas a fim de reduzir seus efeitos patogênicos por meio de substâncias químicas, mecanismos físicos ou biológicos. Esse processo pode ser realizado sob altas concentrações de ozônio $\left(\mathrm{O}_{3}\right)$, peróxido de hidrogênio $\left(\mathrm{H}_{2} \mathrm{O}_{2}\right)$, dependendo da concentração, temperatura e período de exposição (Santos et al., 2010). Por exemplo, um dos métodos usados para eliminar $\mathrm{N}$. coenophialum de sementes consiste em armazená-las em temperatura ambiente por um período superior a um ano (Nunes \& Mittelman, 2016).

A extrusão de cereais e rações também é de extrema importância, pois reduz os níveis de micotoxinas. Adição de adsorventes nutricionalmente inertes, como aluminosilicatos e aluminosilicatos contendo argila, também possuem a capacidade de reduzir a toxicidade de micotoxinas, mas possivelmente pode ter efeito negativo na biodisponibilidade de nutrientes essenciais. $\mathrm{O}$ sal biliar colestiramina funciona como um agente protetor contra micotoxinas. $\mathrm{O}$ uso de polissacarídeos naturais de origem microbiana, incluindo bactérias, leveduras e fungos, é considerado o método de prevenção contra micotoxemias que apresenta os menores efeitos colaterais (Santos et al., 2010). Além disso, deve-se também priorizar um manejo de risco, ou seja, dirigir os produtos sabidamente contaminados com micotoxinas para animais comprovadamente menos sensíveis, ou seja, com menor chance de desenvolver doenças decorrentes desses alimentos. O controle do uso dos mesmos, por meio de regulamentação, também é uma maneira excelente de evitar ou minimizar a contaminação por essas toxinas. Monitorar os níveis de micotoxinas em culturas de plantas e os produtos feitos a partir destas também é uma importante estratégia de manejo (The American Phytopathological Society, 2020).

A melhor e mais econômica estratégia para controlar micotoxinas é a prevenção do crescimento de fungos, através da inspeção de qualidade de matéria prima, do controle de insetos, redução no período de armazenamento da ração e peletização, introdução de antifúngicos, além da adição de compostos adsorventes de micotoxinas incorporados às rações (Reis et al., 2016).

Como forma de tratamento da maioria das micotoxinas, se faz a substituição do alimento com a micotoxina por outro não contaminado, a fim de permitir que o organismo do animal consiga lidar com a quantidade dessa toxina que ainda permaneceu no seu metabolismo. Importante levar em consideração o fato de que os ruminantes conseguem eliminar doses baixas de grande parte destas substâncias quando 
ingeridas, pois a microbiota ruminal tem capacidade de degradá-las nestes casos (Castro et al., 2015). Outra possibilidade estudada é a inclusão na dieta do animal de um adsorvente de toxinas, composto por paredes celulares internas da levedura Saccharomyces cerevisiae e algas, permitindo a recuperação parcial do desempenho quando os animais são alimentados com dieta contaminada (Custodio et al., 2020).

Especificamente, quanto à micotoxicose causada pelo Pithomyces chartarum, as medidas profiláticas adotadas incluem a retirada de bovinos afetados das pastagens contaminadas, assegurar locais com sombra e tratá-los com um protetor hepático à base de Metionina. Ainda, é possível realizar um controle sobre o campo através da remoção da matéria vegetal morta, impedindo a ingestão pelos animais; pastoreamento em períodos diferentes do dia, contagem de esporos e o monitoramento climático e estrutural das pastagens (Rodríguez et al., 2010).

\section{Considerações finais}

Com isso, entende-se que há diversos fungos responsáveis pela proliferação e desenvolvimento de micotoxinas que infectam e adoecem bovinos, como observado anteriormente. Estes fungos, apesar de possuírem nichos distintos, apresentam patogenicidades parecidas que levam a prejuízos notáveis aos rebanhos. Portanto, é indispensável um protocolo de controle e prevenção que vise a saúde e o bem estar do rebanho através da inspeção de qualidade da matéria prima e, em outros casos, utilizar-se da detoxificação dos locais afetados.

\section{Referências bibliográficas}

Brasil. Ministério da Agricultura, Pecuária e Abastecimento. (2009). Manual de Análise Sanitária de Sementes. Secretaria de Defesa Agropecuária - Brasília: Mapa/ACS, 200 p. Recuperado de: https://www.abrates.org.br/files/manual-de-analise-sanitaria-de-sementes.pdf.

Braz, S. C. M., Motta, C. M. S., Massa, D. M. L., Neves, R. P., \& Magalhães, O. M. C. (2009). Viabilidade, confirmação taxonômica e detecção enzimática de espécies de Acremonium preservadas sob óleo mineral na Coleção de Culturas University Recife Mycology. Revista Da Sociedade Brasileira de Medicina Tropical, 42, 63-66. https://doi.org/10.1590/s003786822009000100013.

Castro, I. C., Oliveira, H. F., Mello, H. H. C., \& Mascarenhas, A. G. (2015). Micotoxinas na produção de suínos. Revista Portuguesa de Ciências Veterinárias, 110, 6-13.

Chudzik, G. (2015). Sequência didática: trabalhando o conceito e as características dos fungospesquisa de campo para identificação dos fungos (Trabalho de conclusão de curso). Programa de PósGraduação em Ensino de Ciências Humanas, Sociais e da Natureza (PPGEN), Universidade Tecnológica Federal do Paraná, Londrina, PR, Brasil. Recuperado de: https://repositorio.utfpr.edu.br/jspui/bitstream/1/1648/2/LD_PPGEN_M_Chudzik\%2C\%20Gilberto_2015_1.pdf.

Cunha, K. C., Sutton, D. A., Gene, J., Cano, J., Capilla, J., Madrid, H., Decock, C., Wiederhold, N. P., \& Guarro, J. (2014). Pithomyces species (Montagnulaceae) from clinical specimens: identification and antifungal susceptibility profiles. Medical Mycology, 52(7), 748-757. https://doi.org/10.1093/mmy/myu044.

Custodio, L., Prados, L. F., Figueira, D. N., Yiannikouris, A., Gloria, E. M., Holder, V. B., Pettigrew, J. E., Santin, E., Resende, F. D., \& Siqueira, G. R. (2020). Mycotoxin-contaminated diets and an adsorbent affect the performance of Nellore bulls finished in feedlots. Animal, 14(10), 2074-2082. https://doi.org/10.1017/S1751731120000737.

Delavenne, E., Mounier, J., Asmani, K., Jany, J.-L., Barbier, G., \& Le Blay, G. (2011). Fungal diversity in cow, goat and ewe milk. International Journal of Food Microbiology, 151(2), 247-251. https://doi.org/http://dx.doi.org/10.1016/j.ijfoodmicro.2011.08.029

Dias, A. S. (2018). Micotoxinas em produtos de origem animal. Revista Científica Eletrônica de Medicina Veterinária, 5, 1-15.

Duval, A. M. Q., Henz, G. P., Paz-Lima, M. L., Medeiros, A. R., Miranda, B. E. C., Pfenning, L. H., \& Reis, A. (2010). New hosts of Myrothecium spp. in Brazil and a preliminary in vitro assay of fungicides. Brazilian Journal of Microbiology, 41(1), 246-252. https://doi.org/10.1590/S151783822010000100034 . 
Freire, F. dChagas O., Vieira, I. G. P., Guedes, M. I. F., \& Mendes, F. N. P. (2007). Micotoxinas: importância na alimentação e na saúde humana e animal. Fortaleza: Embrapa Agroindústria Tropical, 48.

Furlong, E. B. (1992). Tricotecenos em trigo: um estudo de metodologia analítica, incidência, contaminação simultânea por outras micotoxinas e de alguns fatores que influem na produção no campo. [sn].

Garvil, M. P., Borges, R., \& Galvão, R. D. V. (2015). Impactos da presença do fungo Penicillium sp na indústria. $E-R A C, 4(1), 1-15$.

Hemckmeier, D., Galindo, C. M., Melchioretto, E., Gava, A., \& Casa, R. T. (2018). Claviceps purpurea e Bipolaris sp. como causa de ergotismo em bovinos no estado de Santa Catarina. Pesquisa Veterinária Brasileira, 38, 875-882. https://doi.org/10.1590/1678-5150-pvb-5130.

Iamanaka, B. T., Oliveira, I. S., \& Taniwaki, M. H. (2013). Micotoxinas em alimentos. Anais Da Academia Pernambucana de Ciência Agronômica, 7, 138-161.

Klich, M. A., \& Pitt, J. I. (1988). A laboratory guide to the common Aspergillus species and their teleomorphs. Commonwealth Scientific and Industrial Research Organization, Division of Food Processing.

Mallmann, C. A., Dilkin, P., Giacomini, L. Z., Rauber, R. H., \& Pereira, C. E. (2007). Micotoxinas en ingredientes para alimento balanceado de aves. Congresso Latinoamericano de Avicultura, 20, 191-204.

Marochi, M. A., Sores, L. M. V., \& Furlani, R. P. Z. (1996). Testes confirmatórios para tricotecenos. Revista Do Instuto Adolfo Lutz, 56(2), 17-20.

Mezzari, A., \& Manole., F. A. (2012). Micologia no laboratório clínico. Manole Ltda.

Morais, R. M., Wicpolt, N. S., Molossi, F. A., Ogliari, D., Mori, A. M., Surkamp, V., \& Gava, A. (2019). Enfermidades neurológicas em bovinos causadas por plantas e micotoxinas no estado de Santa Catarina. Pesquisa Veterinária Brasileira, 39(4), 244-250.

Moreira, N., Martin, C. C., Hilgert, A. R., Tostes, R. A., \& Viott, A. M. (2018). Fotossensibilização hepatógena em bovinos por ingestão de Brachiaria decumbens. Archives of Veterinary Science, 23(1). https://doi.org/10.5380/avs.v23i1.41659.

Motta, A. C., Rivero, G. R.-C., Schild, A. L., Riet-Correa, F., Mendez, M. del C., \& Ferreira, J. L. (2000). Fotossensibilização hepatógena em bovinos no sul do Rio Grande do Sul. Ciência Rural, 30(1), 143-149.

Mussi-Dias, V., Araújo, A. C. O., Silveira, S. F., Rocabado, J. M. A., \& Araújo, K. L. (2012). Fungos endofíticos associados a plantas medicinais. Revista Brasileira de Plantas Medicinais, 14, 261-266. https://doi.org/10.1590/S1516-05722012000200002.

Nunes, C. D. M., \& Mittelman, A. (2016). Ocorrência de fungo endofítico Neotyphodium em sementes de azevém anual do Rio Grande do Sul, Brasil. Embrapa Clima Temperado-Boletim de Pesquisa e Desenvolvimento (INFOTECA-E), 1, 1-22.

Pessoa, C. R. M., Medeiros, R. M. T., Pessoa, A. F. A., Dantas, A. F. M., Oliveira, O. F., \& Riet-Correa, F. (2010). Doença tremorgênica em ruminantes e equídeos no semiárido da Paraíba. Pesquisa Veterinária Brasileira, 30, 541-546. https://doi.org/10.1590/S0100-736X2010000700005.

Pierezan, F., Oliveira Filho, J. C., Carmo, P. M., Lucena, R. B., Rissi, D. R., Togni, M., \& Barros, C. S. L. (2010). Surto de aflatoxicose em bezerros no Rio Grande do Sul. Pesquisa Veterinária Brasileira, 30, 418-422. https://doi.org/10.1590/S0100-736X2010000800001.

Prado, G. (2014). Contaminação de alimentos por micotoxinas no Brasil e no mundo. Revista de Saúde Pública Do SUS/MG, 2(2), 13-26.

Quinn, P. J., Markey, B. K., Leonard, F. C., Fitzpatrick, E. S., \& Fanning, S. (2018). Microbiologia veterinária essencial. Artmed Editora.

Reis, J. S., Xavier, E. G., Rossi, P., NichelleLopes, D. C., Dionello, N. J. L., \& Rutz, F. (2016). Efeitos dos tricotecenos na avicultura e métodos de controle. PUBVET, 6, Art-1399. https://doi.org/10.22256/pubvet.v6n23.1404.

Rodríguez, A., Montossi, F., Luzardo, S., Franchi, M., Lima, A. L., \& López, F. (2010). Aparición de 
Brotes de Intoxicación por "Hongo de la Pradera”(Pithomyces chartarum) en bovinos para carne. INIA, 21(21), 16-19.

Santos, J. S., Ono, E. Y. S., Itano, E. N., \& Hirooka, E. Y. (2010). Zearalenona e desoxinivalenol em trigo brasileiro-cenário sobre necessidade de monitoramento analítico. Biosaúde, 12(1/2), 31-46.

Santos, T. T. (2014). Fungos endofíticos de Phaseolus vulgaris exibem atividade antimicrobiana e potencial para controle de fitopatógenos. Universidade Federal de Viçosa.

Schmidt, S. P., \& Osborn, T. G. (1993). Effects of endophyte-infected tall fescue on animal performance. Agriculture, Ecosystems \& Environment, 44(1-4), 233-262. https://doi.org/http://dx.doi.org/10.1016/0167-8809(93)90049-U

Serrano-Coll, H. A., \& Cardona-Castro, N. (2015). Micotoxicosis y micotoxinas: generalidades y aspectos básicos. Ces Medicina, 29(1), 143-151.

The American Phytopathological Society. (2020). Micotoxinas nas Lavouras (Culturas, pt): Um

Perigo à Saúde Humana e de Animais Domésticos. Zearalenona. Recuperado de: https://www.apsnet.org/edcenter/disimpactmngmnt/topc/Micotoxinas/Pages/ZearalenonePort.aspx

Tibola, C. S., Fernandes, J. M. C., Guarienti, E. M., \& Nicolau, M. (2015). Distribution of Fusarium mycotoxins in wheat milling process. Food Control, 53, 91-95.

Vedovatto, M. G., Bento, A. L., Kiefer, C., Souza, K. M. R., \& Franco, G. L. (2020). Micotoxinas na dieta de bovinos de corte: revisão. Archivos de Zootecnia, 69(266), 234-244. https://doi.org/10.21071/az.v69i266.5119.

Visagie, C. M., Houbraken, J., Frisvad, J. C., Hong, S.-B., Klaassen, C. H. W., Perrone, G., Seifert, K. A., Varga, J., Yaguchi, T., \& Samson, R. A. (2014). Identification and nomenclature of the genus Penicillium. Studies in Mycology, 78, 343-371. https://doi.org/10.1016/j.simyco.2014.09.001.

Histórico do artigo:

Recebido: 11 de março de 2021

Aprovado: 28 de abril de 2021
Licenciamento: Este artigo é publicado na modalidade Acesso Aberto sob a licença Creative Commons Atribuição 4.0 (CC-BY 4.0), a qual permite uso irrestrito, distribuição, reprodução em qualquer meio, desde que o autor e a fonte sejam devidamente creditados. 